\title{
AMBIVALÊNCIA EM MULHERES SUBMETIDAS A LAQUEADURA TUBÁRIA
}

\author{
Ambivalence in women submitted to tubal ligation \\ Ambivalencia en mujeres sometidas a ligación de trompas
}

Gleice Adriana Araújo Gonçalves ${ }^{1}$

Telma Ribeiro Garcia²

Edméia de Almeida Cardoso Coelho³

\section{RESUMO}

Pesquisa exploratória, em que se utilizou o banco de dados de pesquisa envolvendo mulheres submetidas a laqueadura tubária, para determinar, mais acuradamente, a freqüência de mulheres ambivalentes e analisar a distribuição estatística dessas mulheres segundo variáveis selecionadas e o modo como haviam se classificado originalmente em relação ao procedimento (totalmente ou moderadamente satisfeitas, ambivalentes, totalmente ou moderadamente arrependidas). 0 pressuposto do estudo é que, fazendose uma avaliação mais precisa das respostas a várias das questões que lhes foram formuladas, o número de mulheres ambivalentes poderia ser superior ao revelado previamente. Esse pressuposto foi confirmado, observando-se um aumento expressivo de mulheres que tanto tinham motivo para satisfação quanto para arrependimento em relação à laqueadura tubária (mulheres ambivalentes). A análise dos resultados permitiu a compreensão de que a ambivalência em relação à laqueadura tubária é um fenômeno que, embora sujeito a múltiplas determinações, envolve uma parcela muito grande da subjetividade da mulher, tornando complexa sua interpretação.

Palavras-chave: Saúde da Mulher. Direitos Reprodutivos. Esterilização Tubária

\begin{abstract}
Exploratory research, which used the database of a research involving women undergoing tubal ligation, to determine, more accurately, the frequency of ambivalent women and analyze the statistical distribution of these women according to the selected research and how they had originally classified themselves in regard to the procedure (totally or moderately satisfied, ambivalent, totally or moderately regretful). The assumption of the study was that, making up a more accurate assessment of the answers to several of the issues that were asked to them, the number of ambivalent women could be higher than previously disclosed. This assumption was confirmed, being noted a significant increase of women who both had reasons for satisfaction as to regret in relation to tubal ligation (ambivalent women). The results allowed the understanding that the ambivalence regarding tubal ligation is a phenomenon that, subject to multiple determinations, involves a very large portion of the subjectivity of women, making its interpretation a very complex one.
\end{abstract}

Keywords: Women's health. Reproductive rights. Tubal sterilization.

\section{Resumen}

Estudio exploratorio, en que se utilizó la base de datos de una investigación con mujeres sometidas a ligadura de trompas, para determinar, con mayor precisión, la frecuencia de mujeres ambivalentes y analizar la distribución estadística de estas mujeres de acuerdo con variables seleccionadas y la forma en que originalmente se habían clasificado en respecto al procedimiento (totalmente o moderadamente satisfecha, ambivalente, moderada o totalmente arrepentida), en un intento de ampliar la comprensión del fenómeno. El presupuesto del estudio era que, haciéndose una evaluación más precisa de las respuestas a varias de las cuestiones que se plantearon, el número de mujeres ambivalente podría ser superior al previamente divulgado. Esta hipótesis se confirmó, señalándose un aumento significativo de mujeres que tanto había motivo de satisfacción como de arrependimiento en relación a la ligadura de trompas (mujeres ambivalentes). Los resultados permitieron el entendimiento de que la ambivalencia con respecto a la ligadura de trompas es un fenómeno que, sujeto a múltiples determinaciones, implica una gran parte de la subjetividad de la mujer, lo que hace compleja su interpretación.

Palabras-claves: Salud de la Mujer. Derechos reproductivos. Esterilización tubaria.

'Mestre em Enfermagem pela Universidade Federal da Paraíba. Professora Assistente V da Universidade Regional do Cariri - URCA - Ceará e-mail: telmagarciapb@gmail.com. ${ }^{2}$ Doutora em Enfermagem pela Universidade de São Paulo. Professora Adjunto IV e Docente do Programa de Pós-Graduação em Enfermagem, Centro de Ciências da Saúde, Universidade Federal da Paraíba - UFPB. Pesquisadora do CNPq. telmagarciapb@gmail.com ${ }^{3}$ - Doutora em Enfermagem pela Universidade de São Paulo. Professora Adjunto II e Docente do Programa de Pós-Graduação em Enfermagem, Universidade Federal da Bahia - UFBA 


\section{INTRODUÇÃO}

No Brasil, há uma política de assistência à saúde da mulher que comporta o planejamento familiar, para cuja formulação a luta organizada das mulheres pelo direito de regular a fertilidade teve um papel fundamental ${ }^{1}$.

0 planejamento familiar faz parte do Programa de Assistência Integral à Saúde da Mulher do Ministério da Saúde desde 1983, sendo garantido como um direito na Constituição brasileira de 1988. Em 1996, foi promulgada a Lei de Planejamento Familiar, em que estão definidas as regras para a democratização do uso da contracepção e dos meios para assistir a infertilidade 2 . Entretanto, verifica-se no país o uso massivo da esterilização cirúrgica feminina, o método contraceptivo mais utilizado pelas mulheres em idade fértil, com tendência para aumento progressivo de seu uso em idades cada vez menores e realização predominantemente associada a uma cesariana ${ }^{3,4}$.

A dificuldade de acesso aos métodos contraceptivos e o uso pouco eficiente daqueles a que se tem acesso, a que se soma a má qualidade do acompanhamento dos serviços de saúde, são fatores que têm contribuído para que as mulheres recorram em tão grande número à esterilização cirúrgica como principal recurso para regular a fecundidade ${ }^{3-6}$.

Assim, parece ter se consolidado em nosso país uma cultura reprodutiva segundo a qual, ainda muito jovens, as mulheres, por desinformação e ausência de outras alternativas, incluem em seu projeto de vida a cesariana (cujas taxas, no Brasil, têm sobrepujado o parto normal ${ }^{7}$ ) e a laqueadura tubária. Em conseqüência, podem herdar seqüelas, quase sempre definitivas, que levam a sentimentos de arrependimento ou de insatisfaçãa ${ }^{8,9}$, e a uma demanda crescente de cirurgia para reversão da laqueadura ${ }^{5}$.

Os estudos sobre o fenômeno do arrependimento após a realização da esterilização cirúrgica apresentam definições amplas e dificuldades em sua medição. Em alguns casos, fatores de risco presentes, associados a vivências individuais de insatisfação, podem vir a se transformar em arrependimento no futuro ${ }^{9}$, reforçando a tese de que os dois fenômenos insatisfação e arrependimento - não devem ser tratados como dimensões de um mesmo continuum? .

No período de 1997 a 2001, realizou-se a pesquisa Determinantes da esterilização cirúrgica feminina e efeitos secundários ao procedimento ${ }^{10}$, cujo banco de dados foi utilizado para a realização do presente trabalho. Naquela pesquisa, 0 sentimento das mulheres em relação à laqueadura tubária foi investigado por meio das seguintes questões: 1) "se tivesse que decidir hoje pela realização da laqueadura tubária, a senhora: faria outra vez, pensaria duas vezes, não faria outra vez ou não saberia dizer?"; e 2) "em relação à laqueadura das trompas, como a senhora se considera hoje: totalmente satisfeita, moderadamente satisfeita, tanto tem motivo para satisfação quanto para arrependimento (ambivalente), moderadamente arrependida ou totalmente arrependida?".
Embora o percentual daquelas que disseram tanto ter motivos para satisfação quanto para arrependimento fosse 0 menor, observou-se que, ao ser solicitada uma explicação para o modo como se classificaram e, da mesma forma, ao se cruzar essa variável com outras questões formuladas no instrumento da pesquisa, ficavam evidenciadas certas oposições nos discursos das mulheres, que demandavam uma análise mais aprofundada.

Por vezes, a participante se classificava como satisfeita com a laqueadura, mas relatava alterações orgânicas e/ou emocionais atribuídas ao procedimento, ou afirmava que, se tivesse que decidir novamente, não faria a cirurgia. Por seu turno, houve exemplos de participantes que se classificaram como arrependidas, afirmando a seguir haver razões para satisfação, como a despreocupação com a possibilidade de engravidar ou uma vida sexual mais prazerosa. Esses sentimentos opostos ante uma mesma situação não seriam exemplos de ambivalência?

Essa constatação fez supor que, tornando-se a analisar, caso a caso, os instrumentos da pesquisa mencionada, o número de mulheres ambivalentes poderia ser superior ao revelado previamente. Partindo dessas considerações, estabeleceramse como objetivos determinar a freqüência de mulheres ambivalentes, com base no banco de dados da pesquisa determinantes da esterilização cirúrgica feminina e efeitos secundários ao procedimento, e analisar a distribuição estatística dessas mulheres segundo variáveis selecionadas para estudo e o modo como haviam se classificado originalmente em relação ao procedimento, na tentativa de ampliar a compreensão do fenômeno.

Ressalte-se que o termo ambivalência teve origem na Psiquiatria, tendo sido criado por Bleuler, em 1911, para se referir a uma disposição mental patológica do sujeito para manifestar, ao mesmo tempo, sentimentos diametralmente opostos em relação a uma pessoa ou situação ${ }^{11}$. A despeito de sua origem estar vinculada à Psiquiatria, foi verificado que, atualmente, o uso do termo não se restringe a essa área, ou seja, nem sempre ele assume o significado de disposição mental patológica. Assim, o termo ambivalência pode ser empregado com o sentido de hesitação, dúvida, incerteza ou indecisão de um sujeito ante duas ou mais possibilidades ${ }^{12}$. Neste estudo, estamos empregando o termo ambivalência como o estado de quem experimenta, ao mesmo tempo, numa determinada situação, sentimentos opostos ${ }^{13}$.

\section{MÉTODO}

Neste trabalho, cujo projeto foi apreciado e aprovado por Comitê de Ética em Pesquisa, utilizou-se o banco de dados da pesquisa "Determinantes da esterilização cirúrgica feminina e efeitos secundários ao procedimento" ${ }^{10}$, realizada no período 
de 1997 a 2001, que envolveu uma amostra de mulheres submetidas a laqueadura tubária, dentre as quais 3,6\% afirmaram tanto ter motivo para satisfação quanto para arrependimento em relação à laqueadura das trompas (ambivalentes). Entretanto, conforme já afirmado, a leitura dos questionários permitia antever a possibilidade de que, se fosse feita uma avaliação mais precisa das respostas a várias das questões que lhes foram formuladas, um número maior de mulheres poderia ser considerado como ambivalente. Para verificar essa possibilidade, foram realizados os procedimentos descritos a seguir.

Inicialmente, os instrumentos da pesquisa foram separados em cinco grupos distintos, de acordo com o modo original como as participantes classificaram seus sentimentos em relação à laqueadura tubária: totalmente satisfeitas, moderadamente satisfeitas, tanto tem motivo para satisfação quanto para arrependimento (ambivalente), moderadamente arrependidas ou totalmente arrependidas. Foi, então, feita uma reavaliação criteriosa desses questionários, grupo a grupo e caso a caso, para exclusão daqueles sobre os quais não pairassem dúvidas sobre a satisfação ou arrependimento das mulheres em relação à laqueadura tubária.

Nessa reavaliação, foram utilizadas as variáveis tempo decorrido após a laqueadura tubária; ocorrência de problemas de ordem orgânica ou emocional posteriores à laqueadura tubária; existência de possíveis razões para arrependimento; opinião das mulheres sobre como se comportariam se tivessem que aconselhar outra mulher a tomar a decisão relativa ao procedimento e como elas próprias se comportariam se tivessem que tomar novamente a decisão de se submeter à laqueadura tubária, associando-se essas informações com a variável sentimentos em relação à laqueadura tubária: totalmente satisfeita, moderadamente satisfeita, tanto tem motivo para satisfação quanto para arrependimento (ambivalente), moderadamente arrependida ou totalmente arrependida.

Após a reavaliação, foram incluídos neste trabalho 152 questionários referentes a mulheres consideradas pelos pesquisadores como ambivalentes em relação à laqueadura tubária. Submeteram-se os dados desses questionários a tratamento de estatística descritiva, analisando-se a distribuição das 152 mulheres segundo as variáveis já descritas, selecionadas para estudo, e o modo como haviam se classificado originalmente em relação ao procedimento, na tentativa de ampliar a compreensão do fenômeno. Sempre que oportuno, os resultados foram ilustrados com trechos de discursos das mulheres, extraídos de suas respostas a uma questão discursiva incluída no instrumento de coleta de dados.

\section{RESULTADOS}

Foi confirmado o pressuposto de que, reavaliando-se os dados dos questionários da pesquisa "Determinantes da esterilização cirúrgica feminina e efeitos secundários ao procedimento" ${ }^{10}$, o número de ambivalentes poderia ser superior ao revelado previamente, observando-se um aumento expressivo desse número em relação ao total de participantes daquela pesquisa, passando de 35 para 152 mulheres.

\section{Características sociodemográficas e obstétricas da amostra}

Dentre as mulheres consideradas neste estudo como ambivalentes em relação à laqueadura tubária, verificou-se que a idade à época em que os dados foram coletados variou entre o mínimo de 21 e o máximo de 68 anos, com média de 39,8 anos (DP $=8,8 ;$ IC $95 \%= \pm 1,4$ ) e mediana de 39 anos. Quanto ao estado civil por ocasião da coleta de dados, sobressaíram-se 122 (80,3\%) casadas ou em união consensual, valendo destacar a ocorrência de $16(10,5 \%)$ solteiras. Embora 48 (31,6\%) fossem funcionárias de serviço público ou privado e $12(7,9 \%)$ fossem profissionais liberais, predominou a ocorrência de 70 (46,1\%) mulheres que não exerciam ocupação remunerada, valendo destacar também que 20 $(13,2 \%)$ eram empregadas domésticas ou trabalhadoras sem vínculo formal de emprego.

Mais da metade (53,9\%) tinha escolaridade equivalente ao ensino fundamental incompleto. A baixa escolaridade parecia dificultar a inserção nos setores produtivos, por não serem mãode-obra qualificada. 116 mulheres $(76,3 \%)$ referiram um rendimento familiar mensal strês salários mínimos. Tudo somado, pode-se caracterizar essas mulheres como fazendo parte de agrupamentos sociais economicamente desfavorecidos e com aparente dificuldade para ascensão social.

Predominaram mulheres com história obstétrica de quatro gestações ou mais ( $69=45,4 \%$ ), seguidas daquelas com história de duas gestações ( $44=28,9 \%$ ) e de três gestações (38 $=25,0 \%$ ). Quanto à idade por ocasião da primeira gestação, 10 (6,6\%) mulheres tinham menos de 15 anos; 56 (36,8\%) estavam na faixa etária de 15 a 19 anos; e 58 (38,2\%) estavam na faixa etária de 20 a 24 anos quando engravidaram pela primeira vez. Juntas, as três faixas etárias descritas representaram $81,6 \%$, o que permite concluir que essas mulheres haviam iniciado a vida sexual e reprodutiva muito jovens, acompanhando a tendência nesse sentido que vem ocorrendo no Brasil.

Quanto à faixa etária à última gestação, observou-se que 5 $(3,3 \%)$ mulheres tiveram sua última gestação entre 15 e 19 anos e que, cumulativamente, 81 (54\%) tinham idade entre 
20 e 29 anos nessa ocasião. A idade das mulheres ao ser realizada a laqueadura tubária variou entre 19 e 42 anos, com média de 29,3 anos (DP = 5,6; IC 95\% = \pm 0,9) e mediana de 29 anos. Cruzando-se essas duas variáveis, observou-se que, embora a maior parte tenha tido a última gestação e realizado a laqueadura com idade igual ou superior a 25 anos, 46 (30,3\%) mulheres tiveram sua última gestação entre 15 e 24 anos, das quais $37(24,3 \%)$ se submeteram à laqueadura tubária com idade $\subseteq 24$ anos.

Quanto ao estado civil, 134 mulheres (88,2\%) eram casadas ou viviam em união consensual estável; $17(11,2 \%)$ eram solteiras e uma $(0,7 \%)$ era desquitada à época da esterilização cirúrgica. Quarenta e uma (27,0\%) mulheres não haviam usado anteriormente qualquer método contraceptivo, e, entre as que referiram esse uso, o anticoncepcional oral foi referido por $91(59,9 \%)$ mulheres. Os outros métodos citados (tabela, condom e espermicida) alcançaram um percentual de $13,1 \%$.

No que diz respeito aos participantes na tomada de decisão acerca da esterilização, observou-se que ela foi tomada pelo casal em 35,5\% dos casos, o que seria, possivelmente, a alternativa mais adequada. Em 32,2\% dos casos, as mulheres decidiram, sozinhas, submeter-se à laqueadura; em 6,6\% dos casos, a mulher e outra pessoa (externa ao casal) tomaram a decisão, sem que houvesse consulta aos maridos/companheiros.

\section{A ambivalência em relação à laqueadura tubária}

Dentre as 152 mulheres consideradas neste estudo como ambivalentes, $45,4 \%$ não fariam novamente, $26,3 \%$ pensariam duas vezes, $24,3 \%$ fariam novamente e $3,9 \%$ não sabiam dizer como se comportaria se tivesse que tomar novamente a decisão de se submeter à laqueadura tubária. Verificou-se ainda que, aparentemente, a distribuição das mulheres segundo o modo como se comportariam se tivessem que tomar novamente a decisão de se submeter à laqueadura tubária foi aleatória, não guardando relação com o modo original como classificaram seus sentimentos em relação ao procedimento.

No que diz respeito ao tempo decorrido após a laqueadura tubária, há quem considere que as chances de se detectar 0 "verdadeiro" arrependimento são diretamente proporcionais ao tempo decorrido desde que o procedimento foi realizado, ou
Por outro lado, em 3,9\% dos casos, os maridos/companheiros tomaram essa decisão sozinhos, e em 21,7\% dos casos a decisão foi tomada por pessoa externa ao casal.

À exceção da primeira possibilidade, em que a resolução foi do casal, todas as outras representam situações potencialmente problemáticas. Embora o procedimento tenha sido realizado no corpo das mulheres, ressaltem-se os 39 casos $(25,6 \%)$ em que Ihes foi negado o direito de participar da decisão, ou seja, quando os maridos/companheiros decidiram sozinhos ou, o que é ainda pior, quando uma decisão dessa monta foi tomada por pessoa externa ao casal.

As dificuldades financeiras para prover as condições materiais necessárias ao bem-estar dos filhos $(25,7 \%)$ e 0 número de filhos desejado/planejado (12,5\%) representaram uma parcela significativa dentre os motivos para realizar a laqueadura tubária. Entre esses motivos, no entanto, predominou a referência a problemas de saúde $(41,4 \%)$, ocasião em que, quase sempre, o discurso das mulheres buscava apoiar-se em outro, o discurso médico.

[...] Eu só liguei porque foi orientação médica. Eu só tenho dois filhos e eu acho muito pouco para um casal... Então, se não fosse obrigada, eu não teria operado só com dois filhos [...] O médico explicou que eu não poderia ter filho, pois o colo do meu útero era lacrado e nunca ia se dilatar [...] 0 médico me explicou logo que, se eu continuasse a tomar comprimido, a ferida no útero voltaria[...]

seja, quanto maior o tempo pós-laqueadura, maiores as chances de se detectá-lo. Esse sentimento surge, em geral, após seis anos da realização da laqueadura tubária, e só há arrependimento "verdadeiro" quando a mulher expressa desejo de recanalização tubária, o que é diferente de outros tipos de insatisfação como, por exemplo, o desconforto (físico ou emocional) comum na fase de adaptação ao novo estado ${ }^{8}$. Neste estudo, corroborando essa afirmativa, observou-se que 0 arrependimento totalsó foi expresso por mulheres com tempo $\geq 6$ anos, embora algumas com tempo inferior a esse tivessem se considerado originalmente como moderadamente arrependidas ou como ambivalentes em relação ao procedimento (Tabela 1). 
Tabela 1 - Distribuição de mulheres consideradas neste estudo como ambivalentes, segundo tempo decorrido da laqueadura tubária e modo como se classificaram, na pesquisa original, em relação ao procedimento $(n=152)$. Paraíba, 2003.

\begin{tabular}{|c|c|c|c|c|c|c|c|c|c|c|c|c|}
\hline \multirow{3}{*}{$\begin{array}{c}\text { Tempo } \\
\text { decorrido } \\
\text { após a } \\
\text { loqueodura }\end{array}$} & \multicolumn{10}{|c|}{ Modo como se classificorom, no pesquiso original, em reloç6o $\infty 0$ procedimento } & \multirow{2}{*}{\multicolumn{2}{|c|}{ Total }} \\
\hline & \multicolumn{2}{|c|}{$\begin{array}{l}\text { Totalmente } \\
\text { arrependido }\end{array}$} & \multicolumn{2}{|c|}{$\begin{array}{l}\text { Moderadamente } \\
\text { arrependida }\end{array}$} & \multicolumn{2}{|c|}{ Ambivalente } & \multicolumn{2}{|c|}{$\begin{array}{l}\text { Moderodamente } \\
\text { sotisfeito }\end{array}$} & \multicolumn{2}{|c|}{$\begin{array}{c}\text { Totalmente } \\
\text { sotisfeito }\end{array}$} & & \\
\hline & $\bar{f}$ & $\%$ & $f$ & $\%$ & $f$ & $\%$ & f & $\%$ & f & \% & $f$ & $\%$ \\
\hline 1 a 5 onos & - & - & 3 & 2,0 & 11 & 7,2 & 11 & 7,2 & 7 & 4,6 & 32 & 21,1 \\
\hline $\begin{array}{l}6 \text { a } 10 \\
\text { anos }\end{array}$ & 3 & 2,0 & 6 & 3,9 & 10 & 6,6 & 20 & 13,2 & 16 & 10,5 & 55 & 36,2 \\
\hline $\begin{array}{l}11 \text { a } 15 \\
\text { onos }\end{array}$ & 1 & 0,7 & 1 & 0,7 & 6 & 3,9 & 13 & 8,6 & 16 & 10,5 & 37 & 24,3 \\
\hline $\begin{array}{l}16 \text { a } 20 \\
\text { anos }\end{array}$ & . & . & 1 & 0,7 & 2 & 1,3 & 9 & 5,9 & 5 & 3,3 & 17 & 11,2 \\
\hline$>20$ anas & 1 & 0,7 & - & - & 1 & 0,7 & 1 & 0,7 & 8 & 5,3 & 11 & 7,2 \\
\hline Total & 5 & 3,3 & 11 & 7,2 & 30 & 19,7 & 54 & 35,5 & 52 & 34,2 & 152 & 100,0 \\
\hline
\end{tabular}

A ocorrência de problemas, seja de ordem orgânica ou emocional, posteriores à realização do procedimento é outra variável com possibilidade de exercer influência sobre os sentimentos das mulheres em relação à laqueadura tubária ${ }^{8}$. Dessa forma, em busca de indícios para compreender a ambivalência detectada em suas respostas, cruzou-se a variável problemas posteriores atribuídos ao procedimento com o modo como haviam se classificado, na pesquisa original, em relação ao procedimento; com o modo como se comportariam se tivessem que se decidir novamente em relação ao procedimento; e com o modo como se comportariam se tivessem que aconselhar outra mulher em relação ao procedimento.

Tabela 2 - Distribuição de mulheres consideradas neste estudo como ambivalentes, segundo ocorrência de problemas posteriores à laqueadura tubária e modo como se classificaram, na pesquisa original, em relação ao procedimento ( $n=152)$. Paraíba, 2003.

\begin{tabular}{|c|c|c|c|c|c|c|c|c|c|c|c|c|}
\hline \multirow{3}{*}{$\begin{array}{l}\text { Problemos } \\
\text { posteriores, } \\
\text { atribuidos ao } \\
\text { procedimento }\end{array}$} & \multicolumn{10}{|c|}{ Modo como se clossificorom, no pesquiso original, em reloçbo oo procedimento } & \multirow{2}{*}{\multicolumn{2}{|c|}{ Total }} \\
\hline & \multicolumn{2}{|c|}{$\begin{array}{l}\text { Totolmente } \\
\text { orrependida }\end{array}$} & \multicolumn{2}{|c|}{$\begin{array}{l}\text { Moderodamente } \\
\text { orrependido }\end{array}$} & \multicolumn{2}{|c|}{ Ambivalente } & \multicolumn{2}{|c|}{$\begin{array}{c}\text { Moderadamente } \\
\text { satisfeito }\end{array}$} & \multicolumn{2}{|c|}{$\begin{array}{c}\text { Totalmente } \\
\text { sotisfeito }\end{array}$} & & \\
\hline & f & $\%$ & f & $\overline{\mathrm{w}}$ & $f$ & $\overline{\%}$ & f & $\%$ & $f$ & $\bar{\alpha}$ & f & $\bar{q}$ \\
\hline Nenhum & 4 & 2,6 & 7 & 4,6 & 15 & 9,9 & 37 & 24,3 & 31 & 20,4 & 94 & 61,8 \\
\hline $\begin{array}{l}\text { Alteroçōes no } \\
\text { ciclo } \\
\text { menstruol }\end{array}$ & - & - & 1 & 0,7 & 5 & 3,3 & 10 & 6,6 & 10 & 6,6 & 26 & 17,2 \\
\hline $\begin{array}{l}\text { Aleroçóes } \\
\text { psicossomálic } \\
\text { as }\end{array}$ & - & - & 1 & 0,7 & 1 & 0,7 & 2 & 1,3 & 4 & 2,6 & 8 & 5,3 \\
\hline $\begin{array}{l}\text { Aleroçós no } \\
\text { resposta } \\
\text { sexual }\end{array}$ & - & - & - & - & 3 & 2,0 & 1 & 0,7 & 2 & 1,3 & 6 & 3,9 \\
\hline Outro & 1 & 0,7 & 2 & 1,3 & 6 & 3,9 & 4 & 2,6 & 5 & 3,3 & 18 & 11,8 \\
\hline Total & 5 & 3,3 & 11 & 7,2 & 30 & 19,7 & 54 & 35,5 & 52 & 34,2 & 152 & 99,9 \\
\hline
\end{tabular}

Os resultados obtidos nos permitem afirmar que, novamente por fazer a laqueadura tubária. Considerando-se aparentemente, a ocorrência de problemas posteriores à laqueadura tubária não exerceu influência sobre o modo como as mulheres se classificaram em relação ao procedimento. Assim, tanto se observaram mulheres que não referiram qualquer problema em se classificar originalmente como totalmente arrependidas, moderadamente arrependidas ou ambivalentes, como se observaram mulheres se classificarem como totalmente ou moderadamente satisfeitas, a despeito do relato de alterações de ordem orgânica ou emocional pós-laqueadura tubária (Tabela 2).

Dentre as 152 mulheres consideradas neste estudo como ambivalentes, 109 (71,7\%) informaram que não fariam novamente, ou que pensariam duas vezes antes de se decidir essas 109 mulheres em particular, observou-se que 77 $(70,6 \%)$ delas haviam se classificado originalmente como moderadamente ou totalmente satisfeitas com a decisão que haviam tomado de se submeter ao procedimento.

Parece haver, a priori, coerência nas respostas de mulheres que, dada a ocorrência de problemas posteriores, pensariam duas vezes, ou não fariam a laqueadura tubária se tivessem que tomar novamente a decisão. Destaque-se, entretanto, que $20(76,9 \%)$ das que relataram alterações no ciclo menstrual (aumento do fluxo menstrual; dismenorréia); 6 (75\%) das que relataram alterações psicossomáticas (depressão; angústia; irritabilidade) e 3 (50\%) das que relataram alterações na resposta sexual haviam se classificado 
originalmente como moderadamente ou totalmente satisfeitas (Tabela 2).

Tornando ainda mais complexa a interpretação dos dados, observou-se que mais da metade das mulheres $(78=51,3 \%)$ não aconselharia outra mulher a realizar a laqueadura tubária. Mais uma vez, a ocorrência de problemas posteriores à laqueadura tubária não pareceu exercer influência sobre as respostas, pois, dentre as $78(51,3 \%)$ mulheres que não aconselhariam outra mulher a realizar o procedimento, 44 $(56,4 \%)$ não fizeram menção a alterações orgânicas ou emocionais atribuídas à laqueadura tubária. Foi observado também que, dentre as mulheres que não aconselhariam outra mulher a realizar o procedimento, $54(69,2 \%)$ haviam se classificado originalmente como moderadamente ou totalmente satisfeitas com a laqueadura tubária. Se não haviam percebido alteraç̃̃es orgânicas ou emocionais atribuíveis ao procedimento e se estavam satisfeitas com a decisão que haviam tomado, por que não aconselhariam outra mulher a se submeter à laqueadura tubária? De modo coerente, dentre aquelas que não aconselhariam outra mulher a realizar o procedimento, 58 $(74,4 \%)$ não fariam outra vez, ou pensariam duas vezes antes de se submeter novamente ao procedimento. Nesse caso, por que grande parte delas afirmou originalmente estar moderadamente ou totalmente satisfeita com a laqueadura tubária?

Tabela 3 - Distribuição de mulheres consideradas neste estudo como ambivalentes em relação à laqueadura tubária, segundo existência de razões para arrependimento e modo como se classificaram, na pesquisa original, em relação ao procedimento $(n=$ 152). Paraíba, 2003.

\begin{tabular}{|c|c|c|c|c|c|c|c|c|c|c|c|c|}
\hline \multirow{3}{*}{$\begin{array}{l}\text { Raž́es para } \\
\text { arrependimento }\end{array}$} & \multicolumn{10}{|c|}{ Modo original como se clossificaram em relaç60 oo procedimento } & \multirow{2}{*}{\multicolumn{2}{|c|}{ Total }} \\
\hline & \multicolumn{2}{|c|}{$\begin{array}{l}\text { Totalmente } \\
\text { orrependida }\end{array}$} & \multicolumn{2}{|c|}{$\begin{array}{l}\text { Moderodamente } \\
\text { arrependida }\end{array}$} & \multicolumn{2}{|c|}{ Ambivalente } & \multicolumn{2}{|c|}{$\begin{array}{l}\text { Moderodamente } \\
\text { satisfeito }\end{array}$} & \multicolumn{2}{|c|}{$\begin{array}{l}\text { Totalmente } \\
\text { satisfeito }\end{array}$} & & \\
\hline & $\bar{f}$ & $\bar{g}$ & $f$ & $\%$ & $f$ & $\%$ & f & $\%$ & f & $\%$ & f & $\%$ \\
\hline Nenhumo & 3 & 2,0 & 10 & 6,6 & 25 & 16,4 & 38 & 25,0 & 43 & 28,3 & 119 & 78,3 \\
\hline $\begin{array}{l}\text { Desejo de ter } \\
\text { mais um filho }\end{array}$ & - & - & - & - & 1 & 0,7 & 8 & 5,3 & 8 & 5,3 & 17 & 11,2 \\
\hline $\begin{array}{l}\text { Alteraçôes no } \\
\text { estado de } \\
\text { saúde }\end{array}$ & 1 & 0,7 & 1 & 0,7 & 3 & 2,0 & 2 & 1,3 & - & - & 7 & 4,6 \\
\hline $\begin{array}{l}\text { Morte de um } \\
\text { filho }\end{array}$ & 1 & 0,7 & - & . & & . & 1 & 0,7 & 1 & 0,7 & 3 & 2,0 \\
\hline $\begin{array}{l}\text { Problemas } \\
\text { conjugais }\end{array}$ & - & - & - & - & - & - & 1 & 0,7 & - & - & 1 & 0,7 \\
\hline $\begin{array}{l}\text { Mudança no } \\
\text { estado civil }\end{array}$ & - & - & - & - & - & - & 1 & 0,7 & - & - & 1 & 0,7 \\
\hline Outra razōo & $\cdot$ & . & - & . & 1 & 0,7 & 3 & 2,0 & . & . & 4 & 2,6 \\
\hline Total & 5 & 3,3 & 11 & 7,2 & 30 & 19,7 & 54 & 35,5 & 52 & 34,2 & 152 & 100,0 \\
\hline
\end{tabular}

De modo semelhante ao que ocorreu com a variável problemas posteriores atribuídos ao procedimento, o fato de haver ou de não haver razões para arrependimentonão pareceu influenciar o modo como as mulheres se classificaram em relação ao procedimento (Tabela 3). Dentre as 152 mulheres consideradas neste estudo como ambivalentes, $119(78,3 \%)$ informaram não haver e $33(21,7 \%)$ haver razões para arrependimento pós-laqueadura tubária.

Considerando-se as 119 mulheres que não tinham motivos para arrependimento, $81(68,1 \%)$ haviam se classificado originalmente como moderadamente ou totalmente satisfeitas o que, a priori, se pode afirmar ser procedente. Entretanto, 38 $(31,9 \%)$ dessas 119 mulheres, a despeito da inexistência de razões para tal, se classificaram originalmente como totalmente ou moderadamente arrependidas, ou como ambivalentes em relação ao procedimento. Nesse último caso, questiona-se: se não havia razões aparentes, o que levou essas mulheres a se considerar arrependidas ou ambivalentes com a laqueadura tubária?
Torna ainda mais complexa a compreensão do fenômeno a constatação de que, dentre as 33 mulheres que informaram a existência de razões para arrependimento, 24 (72,7\%) haviam se classificado originalmente como moderadamente ou totalmente satisfeitas. Dezessete $(11,2 \%)$ informaram ser o "desejo de ter mais um filho" uma razão para arrependimento pós-laqueadura, dentre as quais $16(94,1 \%)$ haviam se classificado originalmente como moderadamente ou totalmente satisfeitas. Se nutriam o desejo de ter mais um filho, não seria de esperar que tivessem se considerado arrependidas ou, no mínimo, ambivalentes por haver feito a laqueadura tubária?

A segunda razão mais freqüente para arrependimento foi "alteração(ões) no estado de saúde". A esse respeito, vale relembrar que 58 (38,2\%) mulheres informaram a ocorrência de problemas, seja de ordem orgânica ou emocional, posteriores à realização do procedimento. Entretanto, somente 7 delas $(4,6 \%)$ apontaram esses problemas como razão para 
arrependimento. Aparentemente, portanto, na luta para controlar sua fecundidade, as mulheres consideram os efeitos indesejáveis que a laqueadura tubária tem exercido sobre sua saúde física e emocional uma questão de importância secundária.

Considerou-se haver uma certa coerência nas respostas de algumas mulheres que informaram não existir razões para arrependimento e que fariam outra vez a laqueadura tubária se tivessem que tomar novamente a decisão. Quanto às demais, não parece contraditório afirmar que fariam outra vez a laqueadura, a despeito, por exemplo, do desejo de ter mais um filho; ou que pensariam duas vezes ou não fariam outra vez a laqueadura, mesmo não existindo razões para arrependimento?

Como ocorreu com problemas posteriores à laqueadura tubária, os dados obtidos neste estudo permitem afirmar que a variável razões para arrependimento pós-laqueadura não pareceu exercer influência significativa sobre o modo como as mulheres se comportariam se tivessem que aconselhar outra mulher em relação ao procedimento. Verificou-se que, dentre as 78 mulheres que não aconselhariam outra mulher a realizar o procedimento, $16(20,5 \%)$ referiram alguma razão para arrependimento; e que, dentre as 119 mulheres (78,3\% da amostra) que não apresentaram razões para arrependimento, $23(19,3 \%)$ aconselhariam outra mulher a realizar a laqueadura tubária. Da mesma forma, dentre as 109 mulheres que não fariam novamente, ou que pensariam duas vezes antes de se decidir novamente por fazer a laqueadura tubária, 58 (53,2\%) não aconselhariam outra mulher a realizar o procedimento.

Considera-se coerente a opinião das mulheres que referiram razões para arrependimento e que, em vista disso, não aconselhariam outra mulher a realizar o procedimento; das mulheres que não apresentaram razões para arrependimento e que aconselhariam outra mulher a realizar a laqueadura tubária e, finalmente, das mulheres que não fariam novamente, ou que pensariam duas vezes antes de se decidir novamente por fazer a laqueadura tubária e que, também, não aconselhariam outra mulher a realizar o procedimento. Contudo, observou-se que, dentre as 78 mulheres que não aconselhariam outra mulher a realizar o procedimento, $62(79,5 \%)$ não mencionaram razões para arrependimento em relação à laqueadura tubária. Tendo em vista que, dentre essas 78 mulheres, 54 (69,2\%) haviam se classificado originalmente como moderadamente ou totalmente satisfeitas com a laqueadura tubária, considera-se válido perguntar: se, em sua maioria, não tinham razões para arrependimento e estavam satisfeitas com a decisão que haviam tomado, por que não aconselhariam outra mulher a se submeter à laqueadura tubária? Em suas respostas a essa questão, teria sido levado em consideração o respeito à autodeterminação de cada mulher (ou do casal) para tomar uma decisão dessa natureza?

\section{DISCUSSÃO}

Mesmo antes da formulação e aprovação da Lei n ${ }^{\circ} 9.263 /$ 96, regulando o parágrafo $7^{\circ}$ do art. 226 da Constituição Federal, que trata do planejamento familiar, já se falava da necessidade de critérios para realização da laqueadura tubária, entre os quais consideram-se fundamentais $o$ aconselhamento sobre contracepção, com o propósito de que a mulher (ou o casal) entenda os riscos e o caráter irreversível do procedimento; e a informação, o acesso e a disponibilidade de outras opções contraceptivas ${ }^{2-5}$. No entanto, sabe-se que persistem no Brasil problemas das mais variadas ordens na oferta da esterilização cirúrgica feminina 5 .

Os resultados deste estudo corroboram essa afirmativa, ficando evidente a não-aplicação de critérios para a realização do procedimento. Segundo a avaliação de algumas mulheres, essa foi uma decisão possivelmente tomada em momento pouco adequado. Uma das conseqüências do fato de haverem feito uma opção tão séria em momento pouco oportuno, e sem o aconselhamento ou esclarecimentos necessários, fato este que possivelmente pode ser generalizado para uma população mais ampla de mulheres, é o sentimento de ambivalência em relação à decisão tomada.

A ambivalência é um sentimento que, certamente, incomoda a mulher. Entretanto, uma outra conseqüência, ainda mais séria, é a observação que tem sido feita em ambulatórios de Ginecologia, de um número considerável de mulheres arrependidas com a esterilização, expressando o desejo de realizar a recanalização tubária ${ }^{8,9}$.

A perda de um filho após a esterilização é apontada como um dos principais motivos que levam as mulheres a rever a opção pela laqueadura tubária e a desejar voltar atrás ${ }^{5,6}$. Neste estudo, observou-se a presença de mulheres com um filho vivo à laqueadura, o que, aparentemente, atesta a falta de acesso, ou a deficiência na oferta, tanto de métodos contraceptivos reversíveis, quanto de informaç̃es a respeito da contracepção.

A ocorrência observada neste estudo, de esterilização cirúrgica em mulheres solteiras ou separadas, seja essa separação legal ou não, aponta para uma significativa mudança no fenômeno, que demanda atenção. Por um lado, há a possibilidade de que esta tenha sido uma opção deliberada, de mulheres que não desejavam ter mais filhos, a despeito da possibilidade de virem a estabelecer no futuro uma união legal ou consensual. Esse é um direito das mulheres, que consideramos legítimo. Entretanto, há que se levar em consideração, entre outros possíveis, dois aspectos ao ser tomada a decisão de realizar o procedimento: a pequena chance de reversão da laqueadura tubária e a dinamicidade dos seres humanos. Portanto, a possibilidade de que essas mulheres venham a mudar de opinião e a expressar, no futuro, problemas em relação à decisão que foi tomada.

Algumas das informações prestadas pelas mulheres que fizeram parte deste estudo foram consideradas conflitantes. 
Entretanto, há que se compreender que a ambivalência em relação à laqueadura tubária faz parte da ambivalência que caracteriza a anticoncepção no imaginário feminino, envolvendo o dilema da maternidade ${ }^{14}$.

É possível que esse conflito (ou culpa?) permeie o imaginário de muitas das mulheres consideradas ambivalentes neste estudo, para quem a decisão pela laqueadura se deu num contexto de negação de sua autonomia e liberdade reprodutiva, constatada quando se referiram tanto aos participantes da decisão acerca da laqueadura, como aos motivos para realizá-a.

\section{CONSIDERAÇÕES FINAIS}

Objetivou-se neste estudo utilizar o banco de dados de uma pesquisa que envolveu mulheres submetidas a laqueadura tubária, focalizando a ambivalência detectada nas respostas de algumas das participantes, na tentativa de ampliar a compreensão acerca do fenômeno. Entretanto, conforme se observou ao longo da descrição dos resultados obtidos, restaram muito mais perguntas do que explicações; muito mais aspectos que se consideram ainda merecer aprofundamento em estudos posteriores do que aspectos que se deram a conhecer por inteiro; muito mais incertezas do que certezas. Entre essas últimas, a compreensão de que a oscilação (hesitação, dúvida, incerteza ou indecisão) entre a satisfação e o arrependimento, que foi considerada neste estudo o principal atributo da ambivalência em relação à laqueadura tubária, é um fenômeno que, embora sujeito a múltiplas determinações, envolve uma parcela muito grande da subjetividade da mulher.

As mulheres revelaram falta de saber e de controle sobre 0 seu corpo, além de acesso limitado à informação e aos métodos contraceptivos. Somados à decisão pela laqueadura como coação social, gerada pelo constrangimento das necessidades financeiras que dificultam criar mais filhos, os aspectos analisados denunciam a ineficiência do Estado na implementação da política de planejamento familiar e o poder institucional, que confere aos parceiros sexuais e ao profissional de saúde a liberdade de tomar decisões sobre a vida das mulheres.

A elevação da taxa de esterilização em mulheres jovens e com um número reduzido de filhos, sem que os profissionais de saúde discutam a possibilidade de acesso e utilização de outros métodos, ou informem sobre a irreversibilidade da cirurgia, mostra que não se tem tido a devida preocupação com os riscos inerentes a uma esterilização mal conduzida. ${ }^{15}$ Por outro lado, há que se considerar que o fato de a laqueadura tubária ser indicada e realizada pelo médico legitima o procedimento aos olhos da sociedade e, ao mesmo tempo, absolve a mulher de possiveis falhas do método.

Berlinguer ${ }^{15}$, ao analisar o poder da medicina sobre a vida das pessoas e, principalmente, a tendência a transformar em mercadoria ou dinheiro cada parte do corpo e cada ato relativo à saúde das pessoas, afirma que o corpo feminino e a atividade reprodutiva das mulheres têm sido condicionados a um ciclo de medicalização e de mercantilização, ciclo esse que se completa quando aquelas que foram submetidas a uma laqueadura tubária mal conduzida retornam aos serviços de saúde em busca de reversão do procedimento. Neste estudo, além da influência no processo de tomada de decisão, a apropriação e o poder que os profissionais de saúde exercem sobre a vida e sobre o corpo das pessoas estão exemplificados, também, pela referência que foi feita por um número expressivo de mulheres de que não haviam recebido, oportunamente, qualquer informação sobre a irreversibilidade do procedimento.

Acreditamos que uma boa parcela das mulheres que resolvem se submeter à laqueadura tubária o faz, exatamente, em virtude de seu caráter irreversível, pois lhes garantiria "sossego" na vida sexual e reprodutiva. A despeito disso, consideramos que, no âmbito das políticas e das ações de planejamento familiar, a plena informação e o respeito à autodeterminação das mulheres são condições inegociáveis.

\section{Referências}

1. Costa AM. Desenvolvimento e implantação do PAISM no Brasil. In: Giffin K, Costa SH. Questões de saúde reprodutiva. Rio de Janeiro (RJ): FIOCRUZ; 1999. p. 319-35.

2. Ávila MB. A contracepção em debate: velhos conflitos, novas perspectivas. Jornal da Rede Saúde [on- line]. 2000 maio; (20): 3740. Disponível em: http://www.redesaude.org.br/Homepage/ JornaldaRede/JR20/Jornal\%20da\%20Rede\%20n\%BA\%2020.pdf

3. Costa AM, Guilhem D, Silver LD. Planejamento familiar: a autonomia das mulheres em questão. Rev Bras Saude Mater Infant 2006 jan/ mar; 6(1): 75-84.

4. Chacham AS. Cesárea e esterilização: condicionantes socioeconômicos, etários e raciais. J Rede Saúde [on-line]. 2001 mar; (23): 44-47. Disponível em: http://www.redesaude.org.br/ Hom e pa ge/JornaldaRede/JR23/ Jornal\%20da\%20Rede\%20n\%BA\%2023.pdf

5. Hardy E, Bahamondes L, Osis MJ, Costa RG, Faúndes A. Risk factors for tubal sterilization regret, detectable before surgery. Contraception [on- line]. 1996 Sept; 54(3):159-162. Disponível em: h t t p : / / w w w. sci e n cedirect. com/ science?_ob=PublicationURL\&_tockey $=\% 23 \mathrm{TOC}$

\section{\%235008\%231996\%23999459996\%2379232\%23FLP\%2}

\&_cdi $=5008 \& \_$puType $=J \& \_a u t h=y \& \_a c c t=C 000050221 \&$ _version $=1$ \&_urlVersion=0\&_userid $=10 \& \mathrm{md} 5=2115$ c095b4

\section{ce070c539d278d0b505f34}

6. Vieira EM. Do women's attitudes towards abortion and contraceptive methods influence their option for sterilization? Cad Saude Publica [on- line]. 1999 out/dez; 15(4): 739-47. Disponível em: http:// www.scielo.br/pdf/csp/v15n4/1014.pdf

7. Knupp VMAO, Melo ECP, Oliveira RB. Distribuição do parto vaginal e da cesariana no município do Rio de Janeiro no período de 2001 a 2004. Esc Anna Nery Rev Enferm 2008 mar; 12 (1): 39 - 44.

8. Hillis SD, Marchbanks PA, Tylor LR, Peterson HB. Poststerilization regret: findings from the United States Collaborative Review of 
Sterilization. Obstet Gynecol [on-line]. 1999 June; 93(6): 889-95. Disponível em: http://www.greenjournal.org/cgi/reprint/93/6/889

9. Hita MG. Esterilização e raça: pontos para refletir sobre a sexualidade brasileira. In: Anais do $12^{\circ}$ Encontro Nacional de Estudos Populacionais. 2000; Caxambu (MG), Brasil. Belo Horizonte(MG): Associação Brasileira de Estudos Populacionais; 2000. p. 1-25.

10. Garcia TR. Determinantes da esterilização cirúrgica feminina e efeitos secundários ao procedimento. João Pessoa (PB); 2002. Relatório de pesquisa.

11. Porot A. Diccionario de Psiquiatría Clínica y Terapéutica. $3^{\mathrm{a}}$ ed. Barcelona (ES): Labor; 1977.
12. Houaiss A, Villar MS. Dicionário Houaiss da Língua Portuguesa. Rio de Janeiro (RJ): Objetiva; 2001.

13. Anderson KN, Anderson LE, editores. Mosby: dicionário de enfermagem. $2^{a}$ ed. São Paulo (SP): Roca; 2001.

14. Serruya S. Mulheres esterilizadas: submissão e desejo [dissertação de mestrado]. Belém (PA): Núcleo de Altos Estudos Amazônicos/UFPA; 1993.

15. Perpétuo IHO. Uma década de esterilização feminina no Nordeste. In: Anais do $10^{\circ}$ Encontro Nacional de Estudos Populacionais 1996; Caxambu(MG), Brasil Belo Horizonte(MG): Associação Brasileira de Estudos Populacionais; 1996. p. 2612-637.

16. Berlinguer G. Ética da saúde. São Paulo(SP): Hucitec; 1996 